\title{
Insights from corrosion current measurements on corrosion mechanisms in reinforced concrete and on the evaluation of other corrosion data
}

\author{
Ulrich Schneck ${ }^{1, *}$ \\ ${ }^{1}$ CITec Concrete Improvement Technologies GmbH, 01156 Dresden, Germany
}

\begin{abstract}
During the past years Tafel polarization measurements have been implemented into the scope of measurements of CITec corrosion diagnosis projects. This has created a vast database of different and corresponding corrosion parameters, such as chloride and water content in the rebar vicinity, open circuit potential, electrolyte resistance, polarization resistance (from galvanostatic pulse and linear polarization) and corrosion current from Tafel polarization measurements. Although general limitations in using these methods on macro cell systems such as reinforced concrete are known, the comparative assessment of these data has led to a better understanding of the corrosion behaviour and of specific circumstances of the structures which deviated partly from usual expectations. For instance, a low polarization resistance at high chloride content will not result necessarily in a high corrosion current, if the reinforcement in the wider vicinity of the test location is similar active, and cathodic rebar areas are either very distant or retarded by very wet concrete. So the extended range of corrosion testing gives a more precise evaluation of the corrosion situation and permits a tailored repair and maintenance concept to be found. It has also been found that the Stern-Geary equation which is often used to calculate corrosion current densities and material loss of the reinforcement from linear polarization (LPR) measurements, doesn't seem very feasible if used on reinforced concrete structures, as there appears to be a dominant influence of macro cell corrosion over the corrosion model of a homogenous mixed electrode (for which the Stern-Geary equation applies), and the true corrosion current densities may be either larger or (very often) much smaller than those calculated from Stern-Geary. This is not a new observation, and the findings will be discussed for several project cases.
\end{abstract}

\section{Introduction}

The corrosion behaviour of the reinforcement in concrete can also be assessed by enhanced electrochemical methods: AC impedance, galvanostatic pulse, linear polarization or Tafel polarization. With the help of a potentiostat and a measurement cell containing a reference- and a counter electrode (setup according to fig 1), these methods force the rebar - acting as a working electrode - to change its potential from the open circuit value according to the method specifications and to get additional corrosion relevant data: electrolyte resistance, polarization resistance and corrosion current. These data provide enhanced qualitative and also quantitative information which are of better accuracy than those of a potential survey only. This can help to substantially improve the interpretation of the data of a full scale potential survey, even if certain circumstances mainly regarding the LPR and the Tafel polarization are not ideal - e.g. if spots of different, closely neighboured corrosion behaviour may be touched by a single polarization measurement.

Apart from standard laboratory potentiostats, some commercial measuring devices are available for use on reinforced concrete structures.

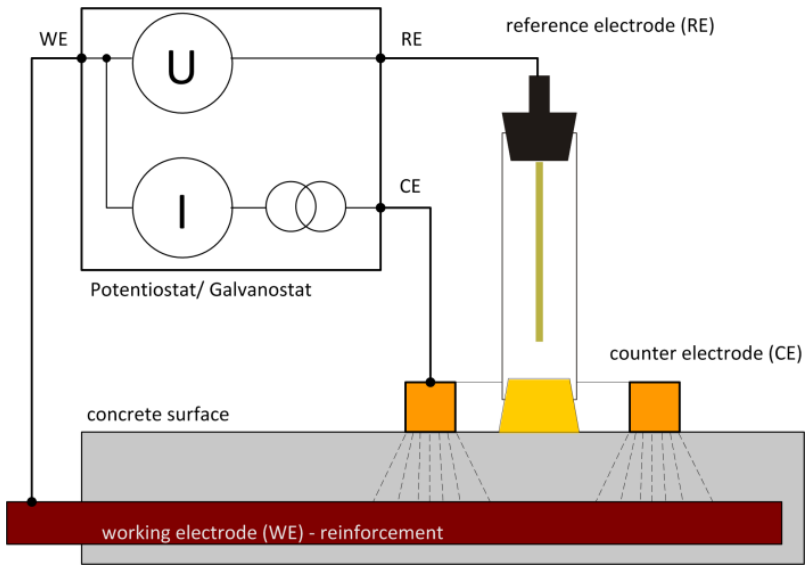

Fig. 1. Measurement setup for corrosion testing with a potentiostat

The equipment used for the measurements (fig 2) of this publication has been described in [1], and meanwhile the control software is able to do numerical and graphical data assessment on the measurement curves. The counter electrode is being operated without guard ring.

Both methods are potentiodynamic measurements, where a shift by either 10 to $20 \mathrm{mV}$ (LPR) or about 200 $\mathrm{mV}$ (Tafel) from the open circuit potential (OCP) is

* Corresponding author: ulrich.schneck@ citec-online.com 
forced into a cathodic direction first, and with a slow speed of ca. $0.5 \mathrm{mV} / \mathrm{s}$ a further shift of the potential until the same respective distance from the OCP into the anodic range is made - see fig 3 .

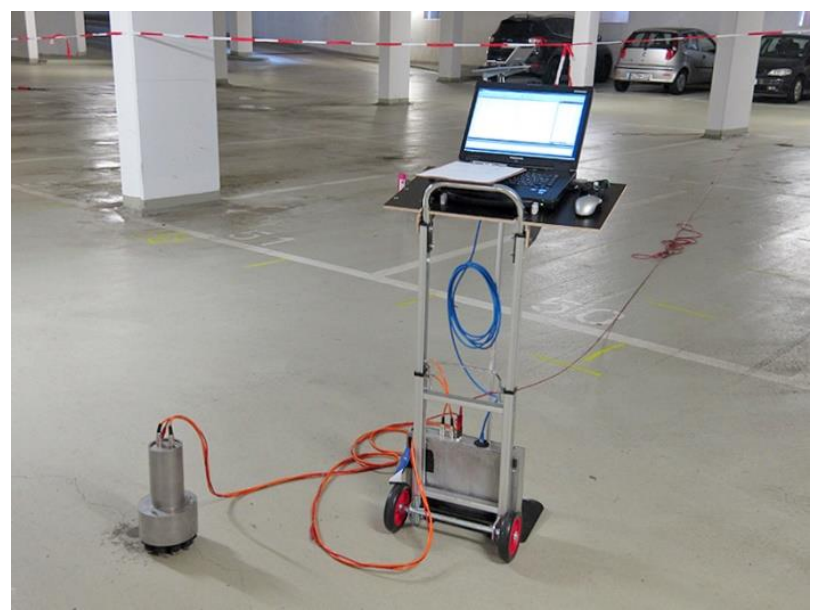

Fig. 2. Corrosion measurement system devices used for the project cases of this publication

During the whole polarization time the required current is recorded and displayed in an E/I diagram for the LPR or in an $\mathrm{E} / \log \mathrm{I}$ diagram for the Tafel polarization.

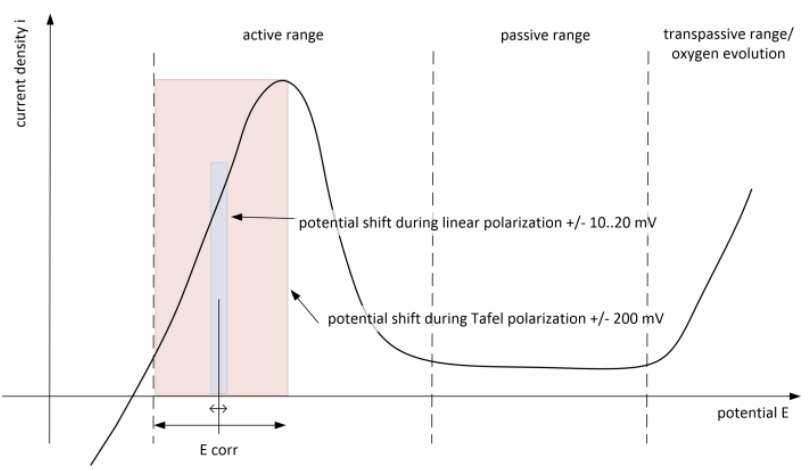

Fig. 3. Polarization scheme for LPR and Tafel measurements on the current density-potential plot

The background consideration for the LPR is that at such a low deviation from the OCP as the mentioned 10 to 20 $\mathrm{mV}$, it can be expected to stay within a linear part on the current-potential curve, so the total polarization resistance can be calculated as

$$
R_{P}{ }^{\prime}=\Delta E / \Delta I
$$

where $\mathrm{R}_{\mathrm{P}}$ ' contains the electrolyte resistance $\mathrm{R}_{\Omega}$ and the polarization resistance $R_{P}$, which is the transfer resistance between metal and electrolyte respectively between rebar and concrete. The measurement curve will give notice if linear conditions applied or not - see figs 4 and 5.

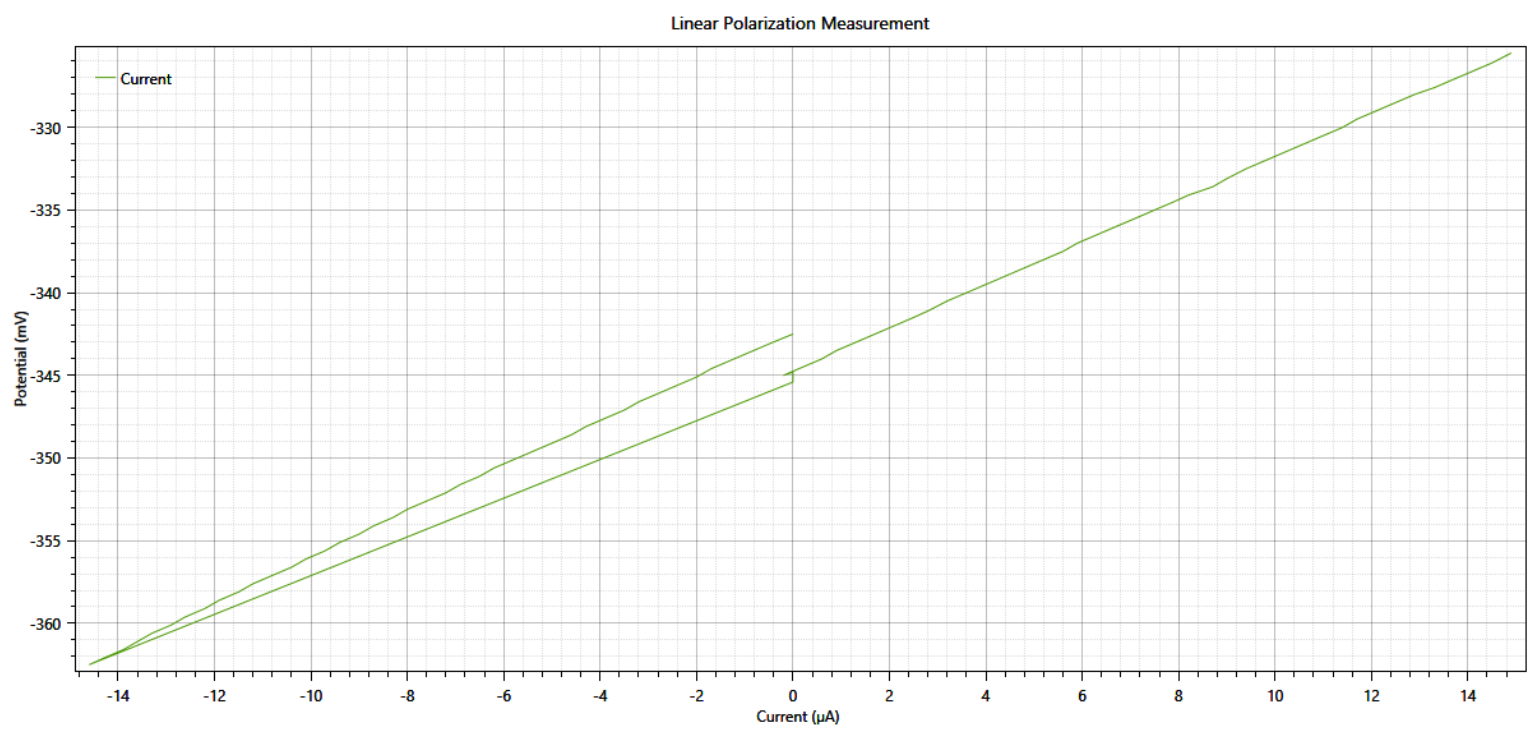

Fig. 4. LPR within the apparent linear current range

The Tafel polarization measurement, which is named after Julius Tafel, an electrochemist, who introduced it about 1905 , is meant to measure the corrosion current at the OCP. This is normally not possible as there's no access into a corrosion element, and the balance of all currents (anodic, cathodic) is Zero on the outside. Typically, the measurement results into a curve according to fig. 5, where the Tafel slopes $b_{c}$ (cathodic slope) and $b_{a}$ (anodic slope) can be fitted. In a graphical assessment, both slopes meet over the OCP, where the externally applied current is zero. The intersection point represents the corrosion current at the OCP (or free corrosion potential $\mathrm{E}_{\text {corr }}$ ), which cannot be measured directly. If related to the polarized rebar area, it results in the corrosion current density, which corresponds to the material loss at the time of investigation. More information about this measurement technique can be found in [2]. 


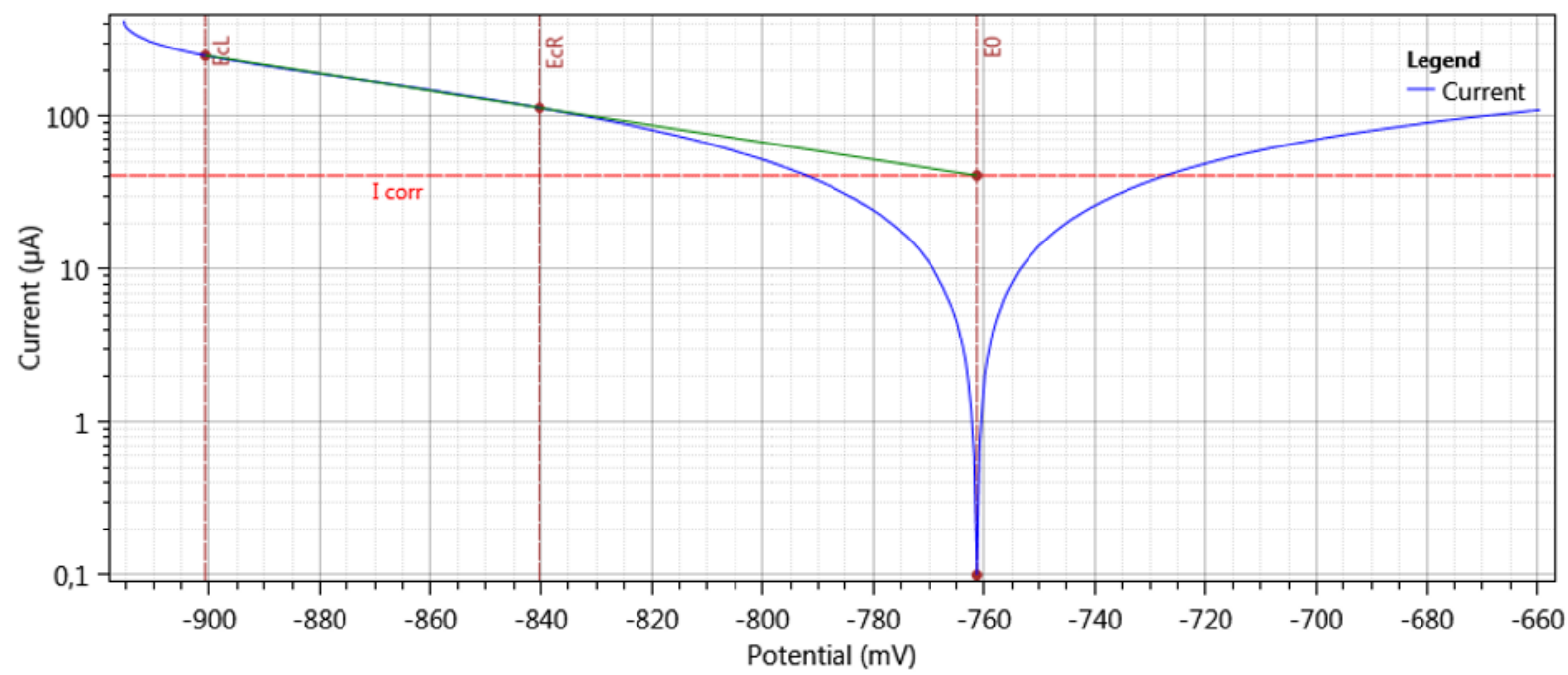

Fig. 5. Typical measurement curve of a Tafel polarization with approach for the corrosion current assessment at the free corrosion potential

For obtaining the correct corrosion current, it is further necessary to do an IR correction, because the recorded data contain a deviation $\Delta \mathrm{E}_{\mathrm{IR}}=\mathrm{I} * \mathrm{R}_{\mathrm{B}}$. The control software of most potentiostats will allow such an IR correction - either by an interruptive method during the measurement or in a separate, later correction of the whole data set. Our own experience with a laboratory potentiostat and its software have shown that the deviation between the uncorrected and the IR corrected results are less than $15 \%$, in most cases less than $10 \%$ (where the IR corrected current is smaller, because the related slopes are steeper). Considering the much larger uncertainties in selecting an appropriate electrode surface, no IR correction has been made in the following assessment, also because the uncorrected result is on the "safe side".

\section{Numerical evaluation of the LPR according to Stern-Geary}

The theory of the assessment and numeric calculation of corrosion current densities is explained comprehensively in several publications, such as [3-5]. Referring to [4], the approach is summarized as following: Close to the corrosion potential $\mathrm{E}_{\text {corr }}$, the current curve is $(\mathrm{E})$ can be expressed in a slope equation

$$
\mathrm{i}_{S}(E)=i_{\text {corr }} * \frac{E-E_{\text {corr }}}{B} \quad\left[\mu A / \mathrm{cm}^{2}\right]
$$

where $\mathrm{B}$ is a constant containing the Tafel slope gradients $b_{a}$ and $b_{c}$ and can be calculated as

$$
B=\frac{b_{a} * b_{c}}{2,303\left(b_{a}+b_{c}\right)}
$$

In the direct vicinity of $\mathrm{E}_{\text {corr, }}$ where the current densitypotential curve can be considered to be a straight line, the gradient of the current equation equals the reciprocal polarization resistance

$$
\frac{d i_{S}(E)}{d E}=\frac{i_{\text {corr }}}{B}=\frac{1}{R_{P}} \quad\left[\mathrm{~cm}^{2} / \Omega\right]
$$

and according to Stern-Geary the corrosion current density $i_{\text {corr }}$ can be calculated at $E_{\text {corr }}$ from the polarization resistance $\mathrm{R}_{\mathrm{P}}$ ' as

$$
i_{\text {corr }}=\frac{\mathrm{B}}{R_{P}} \quad\left[\mu A / \mathrm{cm}^{2}\right]
$$

For corroding reinforcement in concrete, $\mathrm{B}$ can be experimentally obtained as $0.026 \mathrm{~V}$. It is important that both current density and polarization resistance need to be related to the polarized rebar area and are specific values. Another important assumption for the feasibility of the Stern-Geary equation is that the corrosion element is a mixed electrode, having the anodic and cathodic part almost on the same location (which corresponds to micro corrosion as it applies for the general current densitypotential plot). Under these conditions, corrosion current densities calculated or measured from Tafel plots equal the values calculated from LPR measurements.

In reinforced concrete structures we often have macro element corrosion, especially where chloride attack occurs; anodic and cathodic rebar sections may be separated and located in distant areas, which is a different case in principle.

\section{Comparative assessment of corrosion current densities from various projects}

For this assessment 70 LPR and Tafel polarization data couples from 6 recent projects have been used. They represent the entire set of data per project, and most of the measurement locations have been chosen due to apparent high corrosion activity from the potential survey, but also in locations which exhibited rather passive behaviour. The data of following project cases were used:

Underground car park in Munich (UG-1): Large facility (ca. 2,000 $\mathrm{m}^{2}$ per floor) that was closed down 
during a conversion from an office building into a hotel at least 2 years before doing the survey. At parts of the floor slab very large concrete covers $<70 \mathrm{~mm}$ and distinguished areas of either negative or (rather) positive ( $>0 \mathrm{mV}$ vs CSE) potentials with high or low chloride content accordingly; some significant reductions of rebar cross section visible.

Underground car park in Berlin (UG-2): At the time of survey the structure was ca. 45 years old, partly covered by a court area with lawn/ plants and a dwelling/ shopping building. There were severe signs of rust staining and moist concrete due to leaks in joints, numerous cracks; level -1 with frequent change of cars, level -2 with tenant parking and only few car movements.

Multi-storey car park in Braunschweig (CP-1): At the time of survey this was a less frequented structure, but previously heavily affected by de-icing salts; the car park was part of an apartment building, generally penetrated by chlorides, but only moderate corrosion damage because of meanwhile dry concrete (humidity values of $\leq 2.8 \%$ in rebar vicinity).

Underground car park in Kassel (UG-3): Small, onelevel structure with very slim columns in single foundations. Chloride ingress through brick pavement into the soil and by capillary suction into the concrete of the foundations and columns; chloride accumulation on the surface of the columns close above ground and some areas of high corrosion activity

Storm surge barrier at the North Sea (SSB): At the time of survey this ca. 40 year old marine structure with reinforced concrete slabs ca. $40 \times 8 \mathrm{~m}$ was used as a bridge for pedestrians and cyclists on top of the construction, which are exposed to salty environment. Moderate chloride ingress $(<1 \%$ by cement mass in rebar vicinity) found and only few negative potentials $<$ $200 \mathrm{mV}$ vs. CSE in areas of lower concrete cover.

Confined spare area under pedestrian way in Abu Dhabi (CSA): Hollow space (w $\mathrm{x} h=2 \times 0-2 \mathrm{~m})$ underneath an elevated pedestrian way, underpassing a bridge, exposed to salty ground water from the backfill and condensation humidity inside the confined space area. Severe chloride concentration was observed mainly in the walls toward the backfill (up to $3 \%$ by cement with no gradient in $8 \mathrm{~cm}$ depth), but no considerable signs of corroded rebar or loss of cross-section.

The measurement cell has been placed in all cases on a rebar crossing, and the approach for determining the related reinforcement surface was to consider a possible minimum and a maximum surface. The minimum was assumed to be the length of the 2 crossing rebars directly under the counter electrode with a diameter of $60 \mathrm{~mm}$, multiplied by the rebar circumference and a surface factor of 1.2 for the ribs and other deviations from the ideal cylinder. The respective maximum surface was calculated from the double rebar length, assuming a spread of the polarization at $45^{\circ}$ and a concrete cover of $30 \mathrm{~mm}$ as well as a surface factor of 2 for considering corrosion pits. Within that bandwidth the true, but unknown reacting rebar area should be situated, and for a very safe approach the maximum corrosion current density will result when dividing the corrosion current by the minimum surface.

Fig 6 shows all data couples $\mathrm{R}_{\mathrm{P}}$ ' (LPR)/ $\mathrm{I}_{\text {corr }}$ (Tafel) as the received absolute values from the different projects, and in fig 7 a regression curve is fitted in with a remarkably good correlation factor $\mathrm{R}^{2}(0.967)$. For the comparative data in fig 8 the assumed rebar areas have been implemented, and it has been referred to the mentioned minimum area (cylinder under the counter electrode with $\mathrm{d}=60 \mathrm{~mm}$, rebar factor 1.2). This way, both specific parameters $\mathrm{R}_{\mathrm{P}}$ ' (LPR) and icorr (Tafel) result in relatively high values, which can be seen as the "safe" side for $\mathrm{i}_{\text {corr }}$ (Tafel). On the other hand, the $\mathrm{i}_{\text {corr }}$ values calculated by the Stern-Geary equation with $\mathrm{B}=$ 26 are relatively low. Naturally the regression curve of the $\mathrm{i}_{\text {corr }} / \mathrm{R}_{\mathrm{P}}$ values by Stern-Geary needs to show the Stern-Geary equation.

In table 1 the respective minimum, maximum and average $i_{\text {corr }}$ values can be seen per project and in total, resulting either from Tafel polarization or the SternGeary equation, including the percentage of the $i_{\text {corr }}$ by Tafel of the respective $i_{\text {corr }}$ by Stern-Geary.

Figs 9 and 10 show the dependency of the $i_{\text {corr }}$ values on the observed chloride contents in the rebar vicinity. Especially large differences between the $2 \mathrm{i}_{\text {corr }}$ approaches (and extremely high corrosion current densities calculated by Stern-Geary) can be seen for the underground car park Kassel (UG-3), the storm surge barrier (SSB) and the confined space area (CSA). Furthermore, these differences get especially visible at chloride contents of less than $2 \%$.

\section{Discussion}

As mentioned before, the question "how feasible LPR measurements and the calculation of corrosion current densities by the Stern-Geary equation are for reinforced concrete" has been raised before, such as in [6]. There, the background has been described in the light of the difference between the theory of mixed electrodes (with even corrosion on small areas - to which the equation by Stern and Geary refers to) and galvanic elements with the resulting macro element cells, as they are typical for the reinforcement in concrete. In laboratory experiments the effect and influence of separated anodes (carbon steel) and cathodes (stainless steel) in a solution as well as the location of the reference- and counter electrodes during the measurements have been investigated. One finding has been a general underestimation of the true corrosion current density by the calculation of $i_{\text {corr }}$ from $\mathrm{R}_{\mathrm{P}}$ ', as parts of the applied current from the counter electrode will be discharged on other surface areas than the intended measurement location.

The measurements discussed here have been done under practical conditions with many varying, partly unknown parameters that cause difficult conditions and uncertainties for the assessment: concrete permeability, concrete humidity, chloride content, concrete cover, rebar surface and constitution of the corrosion products on the rebar surface. Regardless, both LPR and Tafel polarization measurements have been made, and a first 
observation is that the data couples of the absolute values seem to fit into an apparent scheme (see fig. 8). This indicates some credibility, but a true comparison can be made only when converting these data into specific values.

Furthermore, the feasibility of the Tafel polarizations on reinforced concrete structures needs to be discussed, as the large potential shift of ca. $200 \mathrm{mV}$ in both directions can change the corrosion conditions and hence the received result. By experience, corrosion active surfaces with corrosion products other than the passive layer will exhibit an almost instant, reproducible return on the OCP, which indicates that the change of the conditions by the external polarization is rather negligible. In such situations, the zero current during the Tafel polarization will be seen almost on the OCP where the measurement has been started.

The other mentioned uncertainties come into effect when introducing an area on the rebar, and the choice to take a minimum surface (as would apply for a measurement with a guard ring) results in a maximum current density for the Tafel polarization, so these values are - including the skipped IR correction - on the safe side. This approach has the reciprocal effect on the $i_{\text {corr }}$ values in the Stern-Geary equation, as the also maximized specific $\mathrm{R}_{\mathrm{P}}$ ' values are the lower part of the fraction. All this cannot consider the observations made in (Angst, Büchler 2015), but takes the concrete as a "grey box". It is next discussed how feasible the $\mathrm{i}_{\text {corr }}$ data appears with respect to the project cases:

Underground car park in Munich (UG-1): Here the Tafel- $\mathrm{i}_{\text {corr }}$ values were on average twice as high as the LPR- $i_{\text {corr }}$ values which appears to be plausible as the potential survey made smaller areas of significant negative potentials visible. These were not caused by wet concrete (the whole slab was rather dry after ca 2 years without parking service), so the negative areas (for which the high corrosion currents and current densities were measured), certainly showed chloride induced macro cell corrosion with galvanic elements between small active/ anodic and large passive/cathodic rebar sections.

Underground car park in Berlin (UG-2): The Tafel$\mathrm{i}_{\text {corr }}$ values were on average around $75 \%$ of the LPR- $\mathrm{i}_{\text {corr }}$ value level. Structural problems and water ingress were clearly dominating problems with chloride induced corrosion, so no considerable macro cell corrosion with apparent large cathodes and small anodes could be stated. The high water content determined in parts of the floor slabs will have caused a larger spread of polarization forced by the counter electrode and might have been limiting cathodic reaction by a reduced presence of oxygen. The assumption of referring to a rebar area only in the dimension of the counter electrode was possibly too conservative and a true corrosion activity less than calculated by Stern-Geary seems plausible.

Multi-storey car park in Braunschweig (CP-1): The Tafel-i $\mathrm{i}_{\text {corr }}$ values were very low and on average around
$56 \%$ of the LPR- $i_{\text {corr }}$ value level. This is also plausible as a generally high chloride content was found across the whole floor surface which would have made most of the upper layer of the reinforcement active. In the same way, the availability of passive reinforcement for the cathodic reaction was limited. In the observed moderate to dry concrete the electrolyte resistances could increase which would result in a further retarding of corrosion activity.

Underground car park in Kassel (UG-3): Here the Tafel-icorr values were in a plausible range between passive $\left(0.07 \mu \mathrm{A} / \mathrm{cm}^{2}\right)$ and increased active (1.34 $\mu \mathrm{A} / \mathrm{cm}^{2}$ ), which corresponded to the measured potentials, to the analysed chloride contents and also to the visual appearance of the rebar surface (from blank to heavily corroded). The respective $i_{\text {corr }}$ values calculated from the LPR were on average 6 times higher, where no reason can be found, especially as very high corrosion rates were calculated at locations with low chloride content (see fig 10). The corrosion situation was not a typical macro cell case as the column feet were placed in single foundations with not much rebar surface available as cathode.

Storm surge barrier at the North Sea (SSB): The Tafel- $i_{\text {corr }}$ values were generally in the passive range $(\leq$ $0.20 \mu \mathrm{A} / \mathrm{cm}^{2}$ ) and on average around $27 \%$ of the LPR$\mathrm{i}_{\text {corr }}$ value level. Basically, almost no potential differences were measured; the $\mathrm{R}_{\mathrm{P}}$ ' values were high $(2,200$ to $7,200 \mathrm{Ohm})$ and the $\mathrm{I}_{\text {corr }}$ values low (5 to 23 $\mu \mathrm{A})$, so there was no reason to expect de-passivation and corrosion activity. Since no macro cell corrosion was likely and the reinforcement was visually in a perfect passive state, no explanation for the increased corrosion rates calculated by the Stern-Geary equation could be found.

Confined spare area under pedestrian way in Abu Dhabi (CSA): Regardless of the known high chloride contents the observed corrosion rates from Tafel polarization stayed at a moderate to low level, while the respective $i_{\text {corr }}$ values received from LPR and SternGeary seemed to be extremely high - relatively (more than $800 \%$ of $\mathrm{i}_{\text {corr, }}$, Tafel) and absolutely ( $>17.5$ $\left.\mu \mathrm{A} / \mathrm{cm}^{2}\right)$. Apparently the wet atmosphere caused a lack of oxygen and hence a cathodic control of the corrosion activity similar to submerged concrete in a marine environment. Consequently, concrete deterioration and rebar corrosion were found to be at a very low level.

Among the discussed project cases one (UG-1) was in line with the results of [5], where a macro cell with small anode and large cathode resulted in higher corrosion rates than the LPR evaluation by the SternGeary equation which is meant to characterize a homogeneous mixed electrode. In the other 5 projects it was the opposite case that the corrosion rates determined by the Tafel polarization were lower than those of LPR and Stern-Geary. In 3 of these 5 projects (CP-1, UG-3, CSA) a cathodic control of the otherwise anodic behaving areas was obvious, so its retarding influence could be demonstrated. 


\section{Conclusions}

Regardless of all uncertainties and imperfections, the Tafel polarization seems feasible for the practical assessment of corrosion current densities on reinforced concrete structures, which includes a "safe" approach to do no IR correction to the measurement curve and to relate the $\mathrm{I}_{\text {corr }}$ to a rebar area not greater than the counter electrode. This seems to provide more plausible results than the calculation of $i_{\text {corr }}$ from polarization resistances by the Stern-Geary equation as it could be proven by other project measurement data including the visual inspection of the reinforcement.

An interpretation of the observed differences between the Tafel and LPR assessment is that galvanic elements of macro cells influence the corrosion behaviour on a specific measurement location in either an accelerating way (on small anodes in contact with large cathodes) or a retarding way (limited cathodic reaction by missing or very high water content in the concrete). From another point of view, a measured low $\mathrm{R}_{\mathrm{P}}$ or $\mathrm{R}_{\mathrm{P}}$ ' value is first an indicator if the respective location is active or passive. If active, it depends also on the "outside" conditions (the capability of adjacent cathodic areas) how high the corrosion rate will be. The feasibility of this conclusion should be further investigated as the apparent functional relationship between the data couples of the absolute $\mathrm{R}_{\mathrm{P}}$ ' and $\mathrm{I}_{\text {corr }}$ values as per fig 7 would contradict this approach. It should be mentioned that both measurements contain the IR drop and hence contain the total polarization influenced by the ohmic resistance and the polarization resistance.

If verified, this observation could be used in corrosion surveys: the corrosion rate could be calculated according to Stern-Geary and be compared to the result of the Tafel polarization. If the Tafel corrosion rate at a location of apparent corrosion activity (either because of increased chloride content or because of visible corrosion products on the rebar surface) is significantly lower than the current density resulting from the SternGeary equation, a cathodic control of the corrosion is likely and should be considered when specifying maintenance and repair actions. In the other case (higher corrosion current densities from the Tafel polarization), the typical macro cell corrosion is indicated.

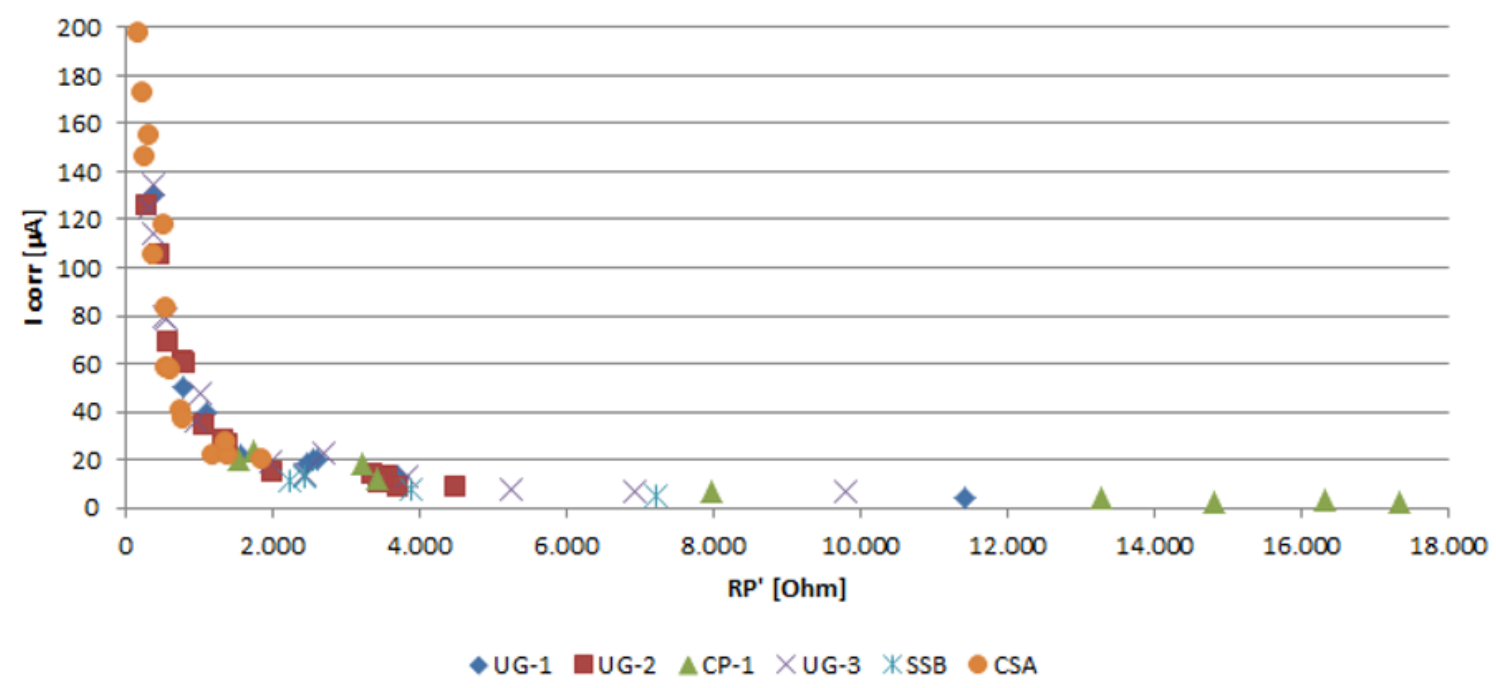

Fig. 6. Data couples of $\mathrm{R}_{\mathrm{P}}$ (LPR) and Icorr (Tafel) as absolute values of the different projects 


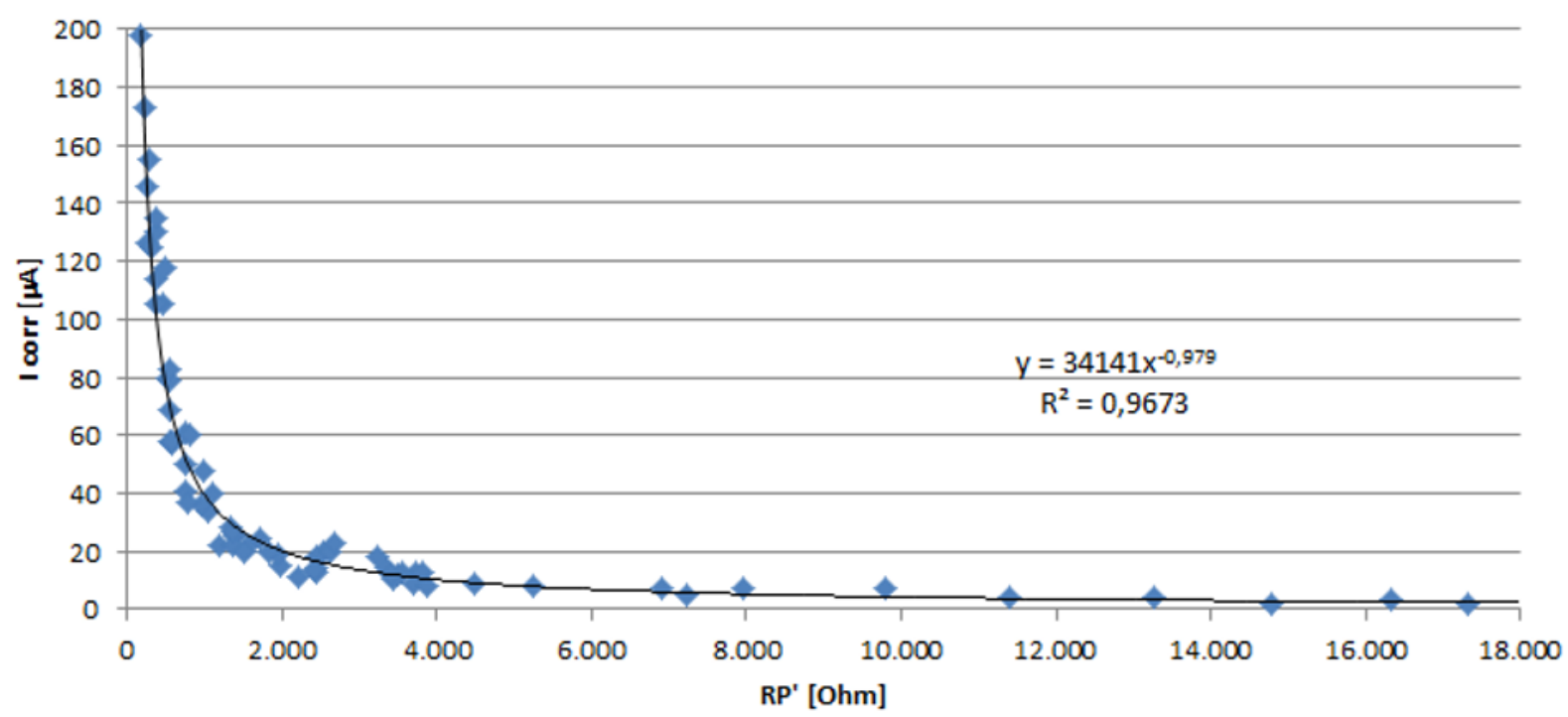

Fig. 7. Unified data couples of absolute RP' (LPR) and Icorr (Tafel) values and regression function

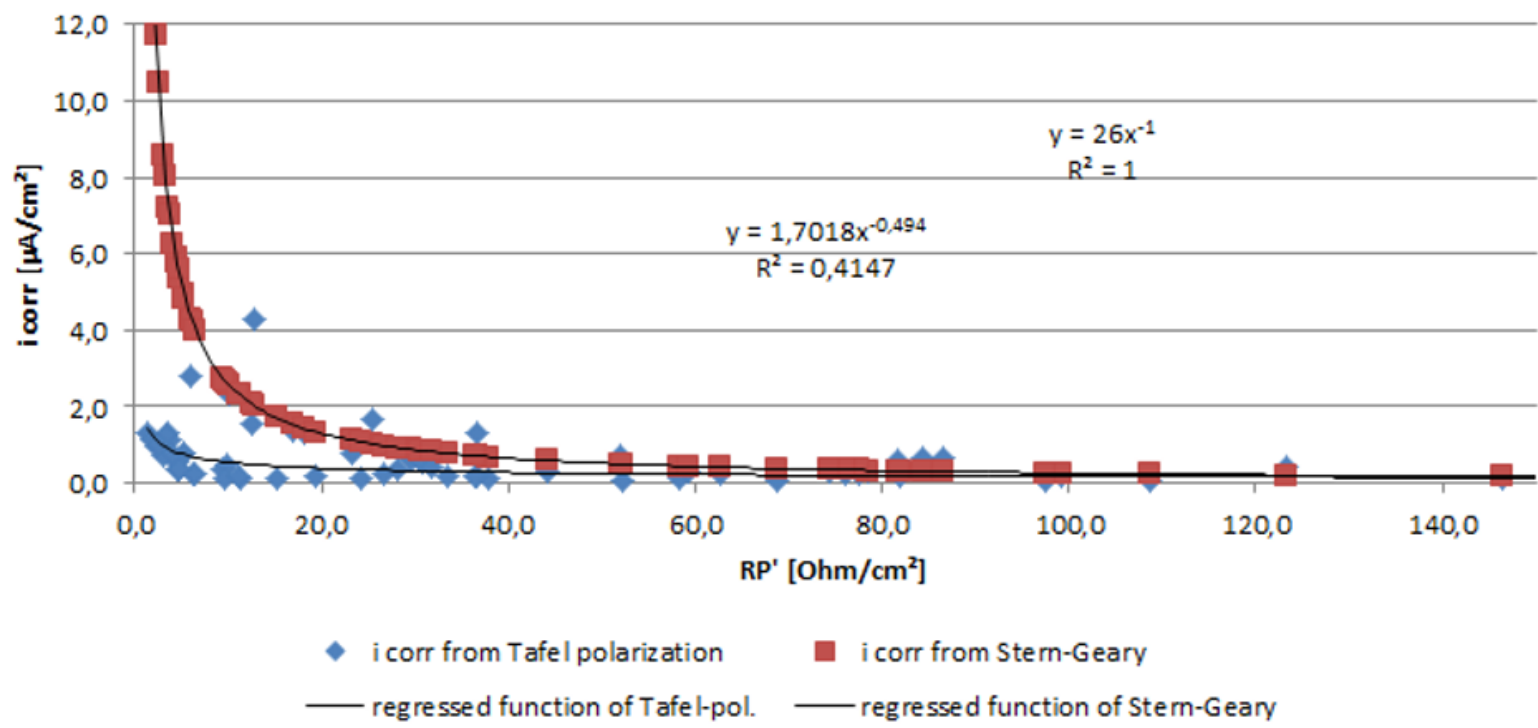

Fig. 8. Specific $i_{\text {corr }}$ values from Tafel polarization and by Stern-Geary, related to specific $\mathrm{R}_{\mathrm{P}}$ ' values

Table 1: comparison of the min, max and avg $\mathrm{i}_{\text {corr }}$ values per measurement method and project

\begin{tabular}{|c|c|c|c|c|c|c|c|}
\hline project & UG-1 & UG-2 & $\mathrm{CP}-1$ & UG-3 & SSB & CSA & total \\
\hline data couples $\mathrm{R}_{\mathrm{P}} / \mathrm{I}_{\text {corr }}$ & 9 & 16 & 10 & 14 & 5 & 16 & 70 \\
\hline \multicolumn{8}{|c|}{ results from Tafel polarization and assumed minimum rebar area $\left[\mu \mathrm{A} / \mathrm{cm}^{2}\right]$} \\
\hline $\min \mathrm{i}_{\text {corr }}$ Tafel & 0.13 & 0.20 & 0.04 & 0.07 & 0.08 & 0.13 & 0.04 \\
\hline $\max i_{\text {corr }}$ Tafel & 4.31 & 2.79 & 0.44 & 1.34 & 0.20 & 1.31 & 4.31 \\
\hline $\operatorname{avg} i_{\text {corr }}$ Tafel & 1.17 & 0.85 & 0.17 & 0.50 & 0.15 & 0.55 & 0.61 \\
\hline \multicolumn{8}{|c|}{ results from Stern-Geary equation, referring to the same rebar area $\left[\mu \mathrm{A} / \mathrm{cm}^{2}\right]$} \\
\hline $\min \mathrm{i}_{\text {corr }} \mathrm{SG}$ & 0.07 & 0.26 & 0.08 & 0.27 & 0.24 & 1.72 & 0.07 \\
\hline $\max \mathrm{i}_{\text {corr }} \mathrm{SG}$ & 2.03 & 4.31 & 0.92 & 8.04 & 0.78 & 17.62 & 17.62 \\
\hline $\operatorname{avg} i_{\text {corr }} S G$ & 0.61 & 1.13 & 0.32 & 3.05 & 0.58 & 6.81 & 2.59 \\
\hline \multicolumn{8}{|c|}{ percentages of the corrosion current density from Tafel polarization compared to Stern-Geary } \\
\hline $\min$ Tafel/SG & $146 \%$ & $56 \%$ & $39 \%$ & $13 \%$ & $22 \%$ & $5 \%$ & $5 \%$ \\
\hline $\max$ Tafel/SG & $221 \%$ & $93 \%$ & $76 \%$ & $26 \%$ & $32 \%$ & $12 \%$ & $221 \%$ \\
\hline avg Tafel/SG & $192 \%$ & $75 \%$ & $56 \%$ & $17 \%$ & $27 \%$ & $8 \%$ & $57 \%$ \\
\hline
\end{tabular}




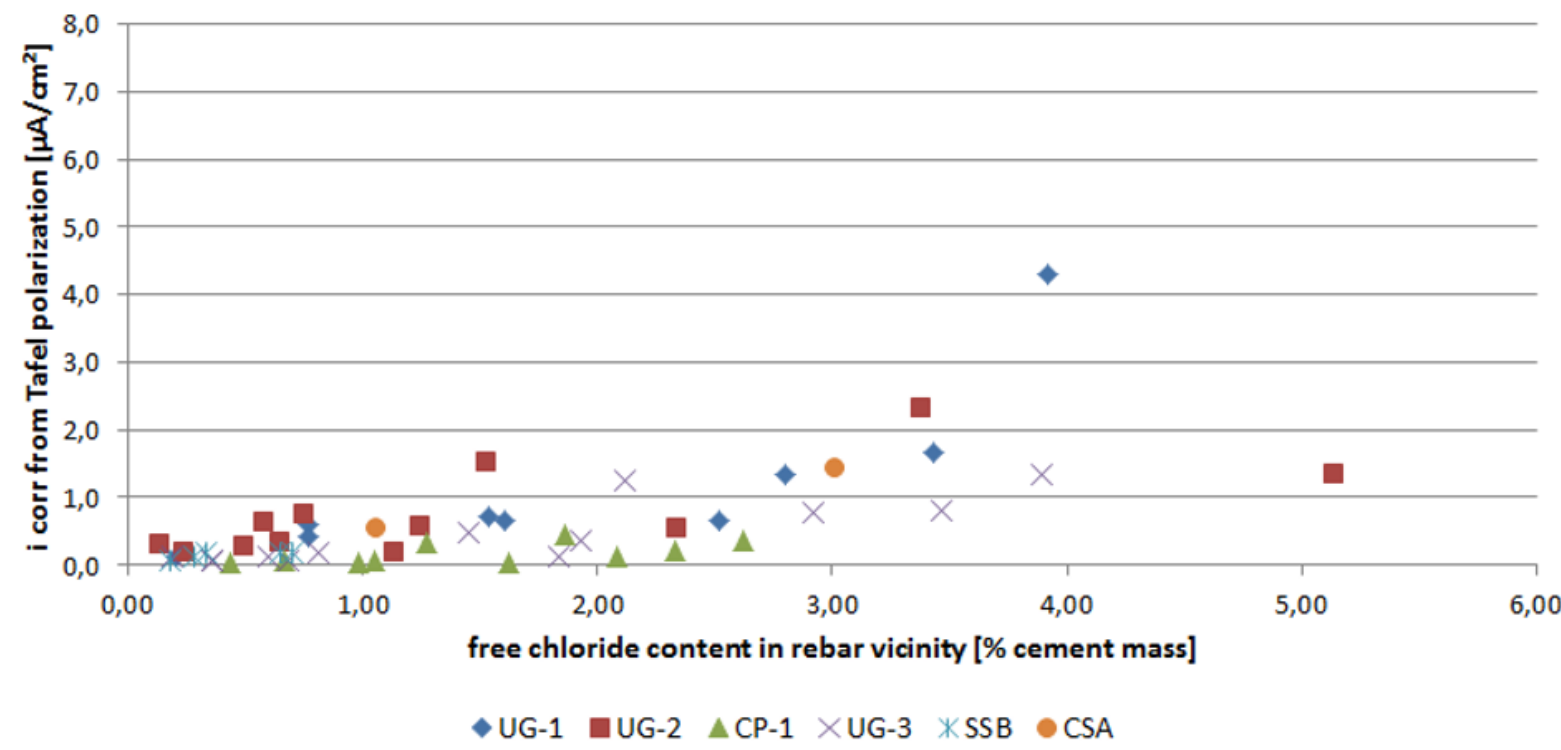

Fig. 9. $i_{\text {corr }}$ values from Tafel measurements as function of the related chloride content in rebar vicinity

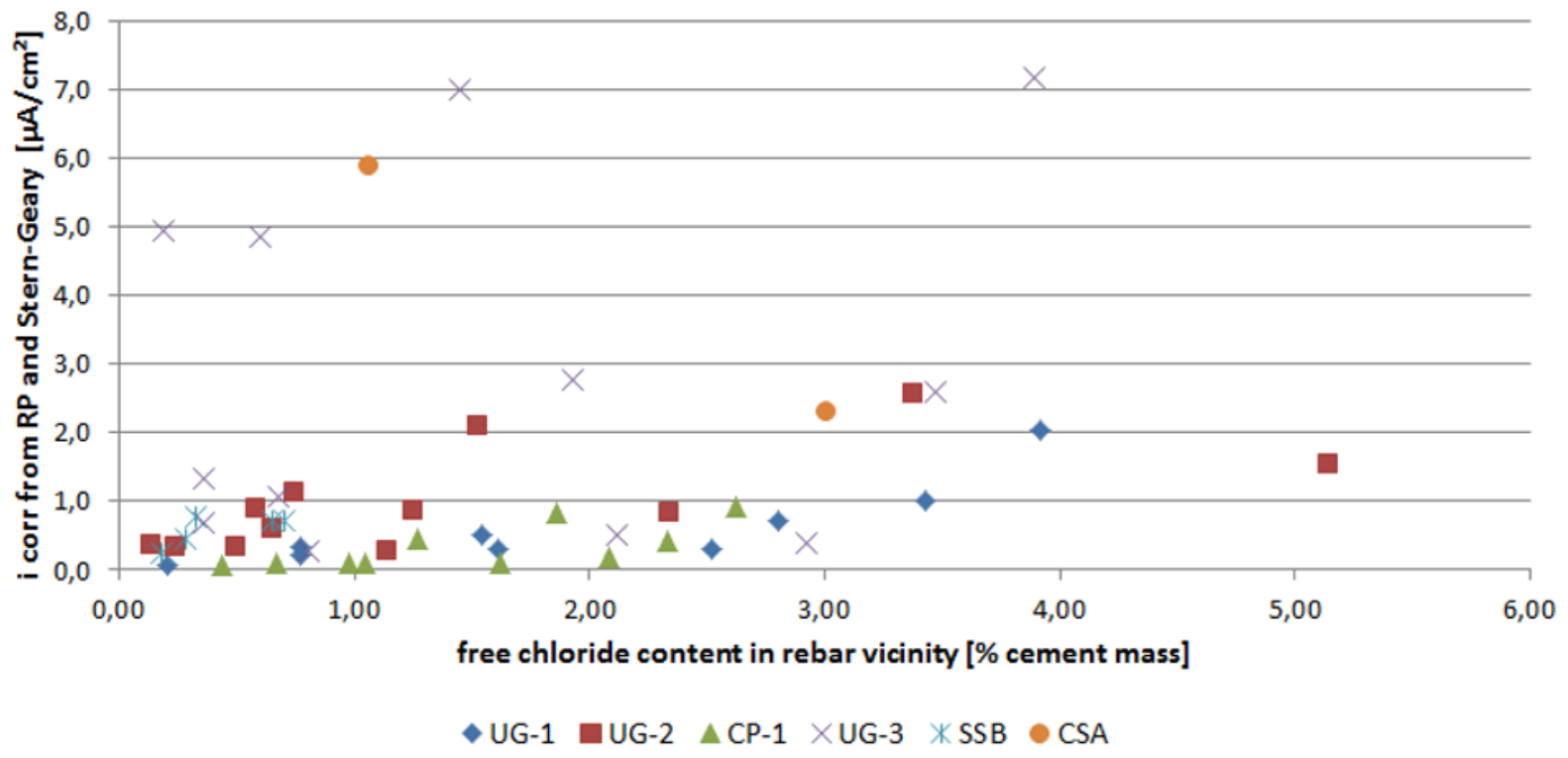

Fig. 10. $i_{\text {corr }}$ values $\mathrm{c}$ as function of the related chloride content in rebar vicinity

\section{References}

1. K. Ahlborn, F. Berthold, W. Vonau, H. Grünzig, U. Schneck, H. Jahn, J. Köhler, Modular Corrosion Measurement System (CMS) for electrochemical NDT. 4th International Conference on Concrete Solutions, Proc. (2011)

2. A. J. Bard, L.R. Faulkner, Electrochemical Methods. Fundamentals and Applications 2nd Edition. Wiley, New York (2001)

3. E. Wendler-Kalsch, H. Gräfen, Korrosionsschadenkunde, Klassiker der Technik (1998)

4. B. Elsener, D. Flückiger, H. Wojtas, H. Böhni,, Methoden zur Erfassung der Korrosion von Stahl in Beton - FA 85/88. ETH Zürich (1996)

5. J. Broomfield, Corrosion of steel in concrete understanding, investigation and repair $2^{\text {nd }}$ Edition. Taylor \& Francis (2007)
6. U. Angst, M. Büchler, On the applicability of the Stern-Geary relationship to determine instantaneous corrosion rates in macro-cell corrosion. Materials and Corrosion 2015, 66, No. 10 (2015) 